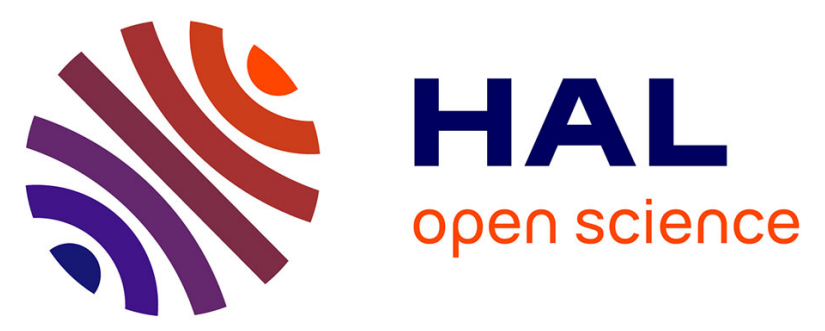

\title{
La0.6Ca0.2Na0.2MnO3 Perovskite: Structural, Magnetic, Critical, and Magnetocaloric Properties
}

Nesrine Mechi, Sobhi Hcini, Bandar Alzahrani, Michel Boudard, Abdessalem

Dhahri, Mohamed Lamjed Bouazizi

\section{- To cite this version:}

Nesrine Mechi, Sobhi Hcini, Bandar Alzahrani, Michel Boudard, Abdessalem Dhahri, et al.. La0.6Ca0.2Na0.2MnO3 Perovskite: Structural, Magnetic, Critical, and Magnetocaloric Properties. Journal of Superconductivity and Novel Magnetism, 2020, 10.1007/s10948-019-05353-9 . hal02442873

\section{HAL Id: hal-02442873 \\ https://hal.science/hal-02442873}

Submitted on 11 Oct 2021

HAL is a multi-disciplinary open access archive for the deposit and dissemination of scientific research documents, whether they are published or not. The documents may come from teaching and research institutions in France or abroad, or from public or private research centers.
L'archive ouverte pluridisciplinaire HAL, est destinée au dépôt et à la diffusion de documents scientifiques de niveau recherche, publiés ou non, émanant des établissements d'enseignement et de recherche français ou étrangers, des laboratoires publics ou privés. 


\title{
La $0.6 \mathrm{Ca}_{0.2} \mathrm{Na}_{0.2} \mathrm{MnO}_{3}$ perovskite: Structural, magnetic, critical and magnetocaloric properties
}

\author{
Nesrine Mechi ${ }^{1,}$, , Sobhi Hcini ${ }^{1}$, Bandar Alzahrani ${ }^{2}$, Michel Boudard ${ }^{3}$, Abdessalem Dhahri ${ }^{4}$, \\ Mohamed Lamjed Bouazizi ${ }^{2}$ \\ ${ }^{I}$ Faculty of Science and Technology of Sidi Bouzid, Research unit of valorization and optimization of \\ exploitation of resources, University of Kairouan, 9100 Sidi Bouzid, Tunisia. \\ ${ }^{2}$ Department of Mechanical Engineering, College of Engineering, Prince Sattam Bin Abdulaziz \\ University, 11942 Alkharj, Saudi Arabia. \\ ${ }^{3}$ University of Grenoble Alpes, LMGP, CNRS, 38000 Grenoble, France. \\ ${ }^{4}$ Monastir University, Sciences Faculty, Laboratory of Physical Chemistry of Materials, Physics \\ Department, Tunisia. \\ * Corresponding authors: E-mail address: nesrine.fstsbz@gmail.com, hassini271185@gmail.com
}

\begin{abstract}
The results of structural, magnetic, critical and magnetocaloric characterizations of $\mathrm{La}_{0.6} \mathrm{Ca}_{0.2} \mathrm{Na}_{0.2} \mathrm{MnO}_{3}$ perovskite have been reported. XRD analysis of the sample synthesized using sol-gel method shows good crystallization in the $R \overline{3} c$ rhombohedral structure. From $M(T)$ curve, a second order ferromagnetic-paramagnetic (FM-PM) phase transition appears at the Curie temperature $\left(T_{C}\right)$ around $275 \mathrm{~K}$. Critical exponents $(\beta, \gamma$ and $\delta)$ have been evaluated using different techniques such as Modified Arrott plots (MAP), Kouvel-Fisher (KF) method and critical isotherm (CI). We found that the critical exponents of the prepared sample agree well with those of the mean-field model. We have also estimated the magnetic entropy change $\left(-\Delta S_{M}\right)$ and relative cooling power $(\mathrm{RCP})$ for the sample which obey power laws as $-\Delta S_{M}=a\left(\mu_{0} H\right)^{n}$ and $R C P=A\left(\mu_{0} H\right)^{N}$, respectively. $\Delta S_{M}$ and RCP values were relatively higher, making the sample promising candidate for magnetic refrigeration technology. The estimated values of the magnetic-ordering parameters ( $n$ and $N$ ) are used to confirm the reliability of the evaluated critical exponent.
\end{abstract}

Keywords: Perovskites; Structural analysis; Magnetic properties; Critical behavior; Magnetocaloric effect. 


\section{Introduction}

Cooling technologies are becoming more important. They are presented everywhere in refrigerators used in all homes up to the largest research laboratories in physics. More recently, the rapid deterioration of the ozone layer, caused in part by $\mathrm{CFC}$ (chlorofluorocarbon) and HCFC (hydrochlorofluorocarbons) gases used in conventional cooling systems based on gas compression and expansion cycles, as well as global warming, is driving researchers to develop more environmentally friendly cooling systems applicable to all temperature ranges, especially around the room temperature. Magnetic cooling, based on the magnetocaloric effect (MCE) materials, is a very good candidate $[\mathbf{1}, \mathbf{2}]$. It has several advantages. The reversibility of the magnetocaloric effect during the magnetization and demagnetization cycles ensures high efficiency. In addition, it would eliminate environmentally harmful gases. Finally, the possibility of manufacturing compact cooling systems and the wide temperature range of use allows a multitude of applications thanks to magnetic refrigeration.

Since, significant and multiple advances have been made at the fundamental and applicative scale in the field of the magnetocaloric systems. Among the most commonly cited materials we found the families of $\mathrm{Gd}$ and $\mathrm{Gd}-\mathrm{Si}-\mathrm{Ge}[\mathbf{3}, 4], \mathrm{LaFe}_{13-\mathrm{x}} \mathrm{Si}_{\mathrm{x}}[\mathbf{5}], \mathrm{MnFeP}_{1-\mathrm{x}} \mathrm{As}_{\mathrm{x}}[\mathbf{6}]$, and Ni-Mn-Ga [7]. The perovskite manganites represent another family which has been widely studied in the magnetic refrigeration area due to their remarkable MCE (see $[1,2]$ for review and references therein).

Our goal in this work is a part of this context. We have identified perovskite manganite having $\mathrm{La}_{0.6} \mathrm{Ca}_{0.2} \mathrm{Na}_{0.2} \mathrm{MnO}_{3}$ composition. The reason for selecting such composition is essentially due to the magnetic properties of the undoped compound La $0.8 \mathrm{Ca}_{0 .} \mathrm{MnO}_{3}$. Indeed, the researches in the magnetic cooling field have been focusing on the search for perovskite materials that displaying larger MCE at Curie temperature $\left(T_{C}\right)$ 
close to room temperature. The $\mathrm{La}_{0.8} \mathrm{Ca}_{0.2} \mathrm{MnO}_{3}$ compound is one of the extensively studied manganites in the literature. This compound has a Curie temperature $\left(T_{\mathrm{C}}\right)$ relatively lower than room temperature [8-11]. On the other hand, the works made on the $\mathrm{La}_{1-\mathrm{x}} \mathrm{Na}_{\mathrm{x}} \mathrm{MnO}_{3}$ system reflect that the addition of $\mathrm{Na}$ instead La leads to the increase of its Curie temperature (see [2] for a review). Therefore, the Curie temperature for $\mathrm{La}_{0.8} \mathrm{Ca}_{0.2} \mathrm{MnO}_{3}$ compound can be approached to room temperature by partial replacement of $\mathrm{La}^{3+}$ by $\mathrm{Na}^{+}$. To verify these observations, we have added in this work an amount of 20 atom $\%$ of $\mathrm{Na}$ instead $\mathrm{La}$ in $\mathrm{La}_{0.8} \mathrm{Ca}_{0.2} \mathrm{MnO}_{3}$ sample. The resulting $\mathrm{La}_{0.6} \mathrm{Ca}_{0.2} \mathrm{Na}_{0.2} \mathrm{MnO}_{3}$ compound was prepared using sol-gel method and characterized using XRD technique in order to verify its purity. The MCE of the sample was also studied by presenting its magnetic, critical and magnetocaloric properties.

\section{Experimental}

To prepare $\mathrm{La}_{0.6} \mathrm{Ca}_{0.2} \mathrm{Na}_{0.2} \mathrm{MnO}_{3}$ perovskite, we have used the sol-gel method. This method is based on the use of citric acid as a complexing agent and ethylene glycol as polymerization agent. We have used stoichiometric proportions of $\left[\mathrm{La}\left(\mathrm{NO}_{3}\right)_{3} \cdot 6 \mathrm{H}_{2} \mathrm{O}\right]$, $\left[\mathrm{Ca}\left(\mathrm{NO}_{3}\right)_{2}\right],\left[\mathrm{NaNO}_{3}\right]$, and $\left[\mathrm{Mn}\left(\mathrm{NO}_{3}\right)_{3} \cdot 4 \mathrm{H}_{2} \mathrm{O}\right]$ nitrates which were dissolved in distilled water, and the solution was subjected to thermal stirring at $90{ }^{\circ} \mathrm{C}$. Thereafter, we have carefully added the ammonia in order to adjust the $\mathrm{pH}$ of the solution to about 7 . After a certain time $\left(\sim 4 \mathrm{~h}\right.$ ), a viscous liquid (gel) is formed. This gel has been dried at $200{ }^{\circ} \mathrm{C}$ (for 6 h) in an oven in order to remove the residual solvent. The obtained precursor is then finely ground and the resulting powder undergoes to some cycles of grinding, pelleting and sintering. Finally, the structure of $\mathrm{La}_{0.6} \mathrm{Ca}_{0.2} \mathrm{Na}_{0 .} \mathrm{MnO}_{3}$ perovskite was well formed at 1100 ${ }^{\circ} \mathrm{C}$ (for $\left.24 \mathrm{~h}\right)$.

X-ray diffraction (XRD) pattern has been registered using "Panalytical X'Pert Pro System" two-circle automatic diffractometer operating at copper wavelength $(\lambda=1.5406 \AA)$ 
with a filter of Nickel to eliminate the $K_{\beta}$ ray. The measurement was made with $0.017^{\circ}$ step and 18 s counting time per step in angular range of $10 \leq 2 \theta \leq 100^{\circ}$. Rietveld method using FullProf software was used for structural parameters estimation [12]. Magnetization measurements were performed using BS1 and BS2 linear extraction magnetometers. Two types of magnetic measurements were made: $M(T)$ curve under a weak magnetic field $\left(\mu_{0} H=\right.$ $0.05 \mathrm{~T}$ ) in the temperature range of $200 \mathrm{~K} \leq T \leq 340 \mathrm{~K}$; and to access the critical behavior and the variation of magnetic entropy change for the sample, the $M\left(\mu_{0} H, T\right)$ isothermal magnetizations were taken as a function of temperature near $T_{C}$ in $0 T \leq \mu_{0} H \leq 5 T$ magnetic field interval.

\section{Results and discussions}

The obtained XRD diffractogram for $\mathrm{La}_{0.6} \mathrm{Ca}_{0.2} \mathrm{Na}_{0.2} \mathrm{MnO}_{3}$ perovskite is shown in Fig. 1. The compound is good crystallized and the majority phase is a perovskite whose diffraction peaks are indexed in $R \overline{3} c$ rhombohedral symmetry. The structural refinement for the sample is shown in the inset of Fig. 1, and the refined structural parameters are listed in

Table 1. In particular, the calculated lattice constants are $a=5.4859$ (1) $\AA$ and $c=13.3963$ (2) $\AA$, with a cell volume of $V=349.15$ (1) $\AA^{3}$. These values are smaller compared to those found for the undoped compound $\mathrm{La}_{0.8} \mathrm{Ca}_{0.2} \mathrm{MnO}_{3}$ [8]. Obviously the Na-substitution of La causes the decrease of lattice parameters in $\mathrm{La}_{0.8} \mathrm{Ca}_{0.2} \mathrm{MnO}_{3}$ sample, in agreement with the results found for $\mathrm{La}_{1-\mathrm{x}} \mathrm{Na}_{\mathrm{x}} \mathrm{MnO}_{3}[\mathbf{1 3}, \mathbf{1 4}]$. The average crystallite size for the sample is estimated using Scherer formula as [15]:

$D=\frac{0.9 \lambda}{\beta \cos (\theta)}$

where $\lambda$ is the employed $\mathrm{X}$-ray wavelength, $\theta$ is the diffraction angle for the most intense peak, and $\beta=\sqrt{\beta_{x}^{2}-\beta_{\text {inst }}^{2}}$ its FWHM (full width at half maximum) with $\beta_{x}$ is the 
experimental FWHM, and $\beta_{\text {inst }}$ is the FWHM of a standard silicon sample. The obtained $D$ value is about $48 \mathrm{~nm}$.

Fig. 2a shows the $M(T)$ curve under magnetic field of $\mu_{0} H=0.05 \mathrm{~T}$ for La0. ${ }_{6} \mathrm{Ca}_{0.2} \mathrm{Na}_{0.2} \mathrm{MnO}_{3}$ perovskite. The $M(T)$ measurement shows a FM-PM phase transition towards the $T_{C}$ which is identified as the minimum of $d M / d T$ curve (inset of Fig. 2a). The FM-PM phase transition occurs at $T_{C}=275 \mathrm{~K}$. This value is significantly higher than the different $T_{C}$ values reported for the pristine sample $\mathrm{La}_{0.8} \mathrm{Ca}_{0.2} \mathrm{MnO}_{3}$ in the literature $\left(T_{C}=221\right.$ $\mathrm{K}$ [8], $183 \mathrm{~K}$ [9], 180.11 K [10] and $210 \mathrm{~K}$ [11]). This reflects that the addition of Na instead $\mathrm{La}$ in $\mathrm{La}_{0.8} \mathrm{Ca}_{0.2} \mathrm{MnO}_{3}$ compound leads to the increase of its Curie temperature. This correlate well with the results found for other Na-doped La perovskite systems (see [2] for a review). The inverse of magnetic susceptibility in the PM region (at $T>T_{\mathrm{C}}$ ) is calculated as $\chi^{-1}(T)=$ $\mu_{0} H / M(T)$ and presented as a function of temperature in Fig. 2b. We can clearly see that the linear variation of $\chi^{-1}(T)$ obeyed the Curie Weiss $(\mathrm{CW})$ law as [16]:

$\frac{1}{\chi(T)}=\frac{T-\Theta}{C}$

where $C$ is the Curie constant and $\Theta$ is the $\mathrm{CW}$ temperature. Eq. (2) is used to fit the $\chi^{-1}(T)$ curve at $T>T_{\mathrm{C}}$, and $C$ and $\Theta$ values are obtained. The obtained value of $\Theta=283 \mathrm{~K}$ has a positive sign which is demonstrating dominant FM interactions between spins for the sample. Based on the obtained $C$ value, we have determined the experimental effective paramagnetic moment $\mu_{\text {eff }}^{\exp }$ of the sample as follows:

$\mu_{e f f}^{\exp }=\sqrt{\frac{3 \times k_{B} \times C \times M_{m}}{N \times \mu_{B}^{2}}}$

with $k_{B}$ is the Boltzmann constant, $M_{m}$ is the molecular mass per unit formula, $N$ is the Avogadro number, and $\mu_{B}$ represents the Bohr magneton. According to Eq. (3), we found $\mu_{\text {eff }}^{\text {exp }}$ as $5.85 \mu_{B}$. This value can be compared with the calculated effective paramagnetic moment $\left(\mu_{e f f}^{c a l}\right)$ as: 
$\mu_{e f f}^{c a l}\left(\mu_{B}\right)=\sqrt{0.4 \times\left[\mu_{e f f}^{t h}\left(M n^{3+}\right)\right]^{2}+0.6 \times\left[\mu_{e f f}^{t h}\left(M n^{4+}\right)\right]^{2}}$

where, $\mu_{e f f}^{t h}\left(M n^{3+}\right) \sim 4.90 \mu_{B}$ and $\mu_{e f f}^{t h}\left(M n^{4+}\right) \sim 3.87 \mu_{B}$ are respectively the $\mathrm{Mn}^{3+}$ and $\mathrm{Mn}^{4+}$ effective magnetic moments. According to Eq. (4), we have calculated $\mu_{e f f}^{c a l}$ value as $4.31 \mu_{B}$. The $\mu_{e f f}^{c a l}$ value is significantly lower than the experimental one. It arises from the presence of short-range FM correlation in the PM state [16].

To understand the magnetic order in $\mathrm{La}_{0.6} \mathrm{Ca}_{0.2} \mathrm{Na}_{0.2} \mathrm{MnO}_{3}$ perovskite, the $M\left(\mu_{0} H, T\right)$ isothermal magnetizations were performed at temperatures around $T_{C}$ and presented in Fig. 3a. With similar behavior to $M(T)$ curve, the $M\left(\mu_{0} H, T\right)$ isotherms gradually decrease with temperature. Also, in the low temperature range, the $M$ values increase non-linearly at low magnetic fields with a tendency to saturation at high magnetic fields reflecting a ferromagnetic behavior, and then the $M$ values vary linearly at high temperature sign of a paramagnetic behavior. In Fig. 3b, we have presented $M^{2} v s . \mu_{0} H / M$ (called as the Arrott plots) [17] which show positive slopes. According to Banerjee's criterion [18], these positive slopes of $M^{2}$ vs. $\mu_{0} H / M$ suggest that $\mathrm{La}_{0.6} \mathrm{Ca}_{0.2} \mathrm{Na}_{0.2} \mathrm{MnO}_{3}$ perovskite has the character of a second-order phase transition.

In order to study the critical behavior for $\mathrm{La}_{0.6} \mathrm{Ca} 0.2 \mathrm{Na}_{0.2} \mathrm{MnO}_{3}$ perovskite near its $T_{C}$ temperature, we conducted an investigation of its critical exponents $(\beta, \gamma$ and $\delta)$. Depending on the mean field theory [19], the Arrott curves $\left(M^{2} v s . \mu_{0} H / M\right)$ as given in Fig. 3b would presented around $T_{C}$ as straight lines, and the isotherm corresponding to $T_{C}$ should pass through the origin. From Fig. 3b, these two conditions are met, indicating that the mean field model is the appropriate model to study the critical behavior of $\mathrm{La}_{0.6} \mathrm{Ca}_{0.2} \mathrm{Na}_{0.2} \mathrm{MnO}_{3}$ perovskite. From Fig. 3b, the linear extrapolation of the data by intersection with the $M^{1 / \beta}$ axis determines the spontaneous magnetization $M_{S}$ (below $T_{C}$ ) and the linear extrapolation by intersection with $\left(\mu_{0} H / M\right)^{1 / \gamma}$ axis allows to determine the values of the inverse initial 
susceptibility $\chi 0^{-1}$ (above $T_{C}$ ). Then, the data of $M_{s}(T)$ and $\chi 0^{-1}(T)$ were respectively adjusted in Fig. 4a using the two following equations [20].

$M_{S}(T)=M_{0}(-\varepsilon)^{\beta} \quad\left(\right.$ with $\varepsilon<0$ and $\left.T<T_{C}\right)$

$\chi_{0}^{-1}(T)=\left(\frac{h_{0}}{M_{0}}\right) \varepsilon^{\gamma} \quad\left(\right.$ with $\varepsilon>0$ and $\left.T>T_{C}\right)$

where $M_{0}$, and $h_{0} / M_{0}$ designate the critical amplitudes, and $\varepsilon=\left(T-T_{C}\right) / T_{C}$ is the reduced temperature. The fitting results are shown in Fig. $\mathbf{4 a}$, and the estimated values of $\beta$ and $\gamma$ agree well with those of the mean field model. Another estimation of the exponents' $\beta$ and $\gamma$ can be achieved more exactly using the Kouvel-Fisher (KF) method according the following equations [20]:

$M_{S}(T)\left[\frac{d M_{S}(T)}{d T}\right]^{-1}=\frac{\left(T-T_{C}\right)}{\beta}$

$\chi_{0}^{-1}(T)\left[\frac{d \chi_{0}^{-1}(T)}{d T}\right]^{-1}=\frac{\left(T-T_{C}\right)}{\gamma}$

Fig. $4 \mathbf{b}$ shows the $M_{S}(T)\left[\frac{d M_{S}(T)}{d T}\right]^{-1}$ vs. $T$ and $\chi_{0}^{-1}(T)\left[\frac{d \chi_{0}^{-1}(T)}{d T}\right]^{-1}$ vs. $T$ curves. The linear adjustments of these plots using Eqs. (7) and (8) allowed us to determine the $\beta$ and $\gamma$ values which are also very close to those of the mean field model. Concerning the third exponent $(\delta)$, it is possible to obtain it directly by adjusting the critical isotherm $(\mathrm{CI}), M\left(T_{C}, \mu_{0} H\right)$, according to this relation:

$M=D\left(\mu_{0} H\right)^{1 / \delta} \quad\left(\right.$ with $\varepsilon=0$ and $\left.T=T_{C}\right)$

As illustrated in Fig. 5, we found $\delta=3.030 \pm 0.014$. This value can be checked form the $\beta$ and $\gamma$ values previously determined according to Widom relation given as [21]:

$\delta=1+\frac{\gamma}{\beta}$

This equation gives $\delta=3.104$ and 3.077 when the values of $\beta$ and $\gamma$ are taken respectively from Fig. 4a and b. These values correlate well with the $\delta$ value estimated from the CI. This 
compatibility can be also supported by the state equation in the critical region given, according to Stanley's scaling hypothesis, as follows [20]:

$M(H, \varepsilon)=|\varepsilon|^{\beta} f_{ \pm}\left(\frac{\mu_{0} H}{|\varepsilon|^{\beta+\gamma}}\right)$

where $f_{+}$and $f_{\text {- }}$ are regular analytical functions defined at temperatures below and above $T_{C}$, respectively. By using the $\beta$ and $\gamma$ values obtained by KF method, we presented in Fig. 6 the plots of $\left(M|\varepsilon|^{-\beta}\right)$ vs. $\left(\mu_{0} H|\varepsilon|^{-(\beta+\gamma)}\right)$ which collapse into two separate branches near $T_{C}$. This is another argument which confirms the well estimation of the critical exponents of the present sample. In Table 2, we have compared the critical exponents of $\mathrm{La}_{0.6} \mathrm{Ca}_{0.2} \mathrm{Na}_{0.2} \mathrm{MnO}_{3}$ perovskite (present work) with those of the theoretical models [20]. As shown in the table, the critical exponents are near the ones of the mean field model. In this case, the universality class of the magnetic phase transition for our sample which depends on the exchange interaction range can be checked by the equation of the exchange integral as follows [22]:

$J(r)=1 / r^{d+\sigma}$

where $d$ designed the dimension of the system, and $\sigma$ represents the range of interaction. It has been demonstrated that the 3D-Heisenberg exponents $(\beta=0.365, \gamma=1.336, \delta=4.8)$ are valid if $\sigma \geq 2$, the mean- field exponents $(\beta=0.5, \gamma=1$ and $\delta=3)$ occur if $\sigma$ is less than $3 / 2$, however for the intermediate range $3 / 2<\sigma<2$, the exponents belong to different universality classes which depends upon $\sigma$. For our sample, the compatibility of $\beta, \gamma$ and $\delta$ values with those of the mean field model indicates that the exchange integral for $\mathrm{La}_{0.6} \mathrm{Ca}_{0.2} \mathrm{Na}_{0.2} \mathrm{MnO}_{3}$ perovskite can be varies as $J(r)<r^{-5}$.

The isothermal variation of the magnetic entropy $\left(\Delta S_{M}\right)$ was calculated from the experimental isothermal magnetizations curve $M\left(H, \mu_{0} H\right)$ by the application of the following Maxwell relation [2]:

$\Delta S_{M}\left(T, \Delta \mu_{0} H\right)=\int_{0}^{\mu_{0} H}\left(\frac{\partial M}{\partial M}\right)_{H} d H$ 
where $\mu_{0} H$ is the applied magnetic field. The results obtained for applied fields of 1 to $5 \mathrm{~T}$ are shown in Fig. 7a for $\mathrm{La}_{0.6} \mathrm{Ca}_{0 .} \mathrm{Na}_{0 .} \mathrm{MnO}_{3}$ perovskite. The magnetic entropy change reaches a maximum peak near the order temperature as $\left|\Delta S_{M}^{\max }\right|=3.09 \mathrm{~J} \cdot \mathrm{kg}^{-1} \cdot \mathrm{K}^{-1}$ at $\Delta \mu_{0} H=5 \mathrm{~T}$. This value is significantly high. As a result, the sample can be used in magnetic refrigeration technology. For comparison, the $\left|\Delta S_{M}^{\max }\right|$ values of certain perovskites [23-31] are given in Table 3.

In other part, concerning the magnetic-field correlation of $\Delta S_{M}$ for samples having second-order PM-FM magnetic phase transitions, Oesterreicher and Parker [32] have dismounted that this correlation can be expressed as:

$-\Delta S_{M}=a\left(\mu_{0} H\right)^{n}$

where $a$ is a constant, and $n$ is an exponent which depends on the magnetic state of the sample. For a ferromagnetic material, $n=2$ above its Curie temperature $T_{C}$, and $n=1$ below its $T_{C}$. According to the mean field approach, the $\Delta S_{M}\left(\mu_{0} H\right)$ obeys a power function with $n=2 / 3$ at $T_{C}$. Moreover, the exponent $n$ can be expressed at $T_{C}$ versus the critical exponents $(\beta, \gamma$ and $\delta)$ as [33]:

$n\left(T_{C}\right)=1+\frac{\beta-1}{\beta+\gamma}$

and

$n\left(T_{C}\right)=1+\frac{1}{\delta}\left(1-\frac{1}{\beta}\right)$

By adjusting the $\Delta S_{M}\left(\mu_{0} H, T_{C}\right)$ isothermal using Eq. (14) in Fig. 7b, the $n$ value is estimated as $n=0.675 \pm 0.015$. The obtained $n$-value is close to the mean field prediction $(n=2 / 3)$. On the other hand, taking into account the values of $\beta$ and $\gamma$ previously determined from $\mathrm{KF}$ method (Fig. 4b and Table 2), and the $\delta$-value deduced from the CI (Fig. 5 and Table 2), the $n$-values are found as 0.664 and 0.666 by using Eqs. (15) and (16), respectively. These values are very close to that obtained at $T_{C}$ using Eq. (14). These results confirm the well estimation 
of the critical exponents for $\mathrm{La}_{0.6} \mathrm{Ca}_{0.2} \mathrm{Na}_{0.2} \mathrm{MnO}_{3}$ sample. The relative cooling power (RCP) of a material is defined as the integrated area under the $\Delta S_{M}(T)$ curve with the temperatures corresponding to the half-height values of the magnetic entropy variation peak $(\delta T)$ as bounds of integration. The RCP values at different applied fields are estimated according the following relation [2]:

$R C P=\left|\Delta S_{M}^{\max }\right| \times \delta T_{F W H M}$

For $\Delta \mu_{0} H=5 \mathrm{~T}$, the RCP value is about $214 \mathrm{~J} \mathrm{~kg}^{-1}$. This value is reported in Table 3 besides those of some perovskite materials at the same magnetic applied field. It has been shown that the magnetic-field variation of the RCP can be expressed as the following power law [34]:

$R C P=A\left(\mu_{0} H\right)^{N}$

where $N$ is the critical exponent of the magnetic transition. The estimated $N$-value from the $R C P\left(\mu_{0} H\right)$ for $\mathrm{La}_{0.6} \mathrm{Ca}_{0.2} \mathrm{Na}_{0.2} \mathrm{MnO}_{3}$ sample is found as $N=1.335 \pm 0.004$ (see the fit in Fig. 7b). This value is higher than those previously found for other systems [34-36] and the one reported for Gd alloy ( $N=1.16)$ [37]. According to V. Franco et al. [38]:

$N=1+\frac{1}{\delta}$

From Eq. (19) and using the estimated $N$-value, we calculated the value of $\delta$ exponent as $\delta=$ 2.985. This value agrees well with those estimated from the CI $M\left(T_{C}, \mu_{0} H\right)$ and Widom relation. This result confirms the well correlation between the critical behavior and MCE analyses performed for $\mathrm{La}_{0.6} \mathrm{Ca} 0.2 \mathrm{Na}_{0.2} \mathrm{MnO}_{3}$ perovskite. 


\section{Conclusion}

La $0.6 \mathrm{Ca}_{0 .} \mathrm{Na}_{0.2} \mathrm{MnO}_{3}$ perovskite has been synthesized using sol-gel method. XRD measurement shows a perovskite phase whose diffraction peaks are well indexed in the $R \overline{3} c$ rhombohedral symmetry. The sample presents a second order FM-PM magnetic phase transition at Curie temperature equal to $275 \mathrm{~K}$. The critical exponents study for the sample shows that the critical behaviour is described in the mean field model with an exchange integral varying as $J(r)<r^{-5}$. The estimated values of magnetic entropy and RCP indicate that the sample can be used in the magnetic refrigeration technology. Finally, the magnetic field variations of $\triangle S_{M}$ and $R C P$ were used to confirm the reliability of the critical exponents estimated for the sample.

\section{Acknowledgements}

This work was supported by the Deanship of Scientific Research at Sattam Bin Abdulaziz University under the research Project Number 2017/01/7246. 


\section{References}

[1] N. Raghu Ram, M. Prakash, U. Naresh, N. Suresh Kumar, T. Sofi Sarmash, T. Subbarao, R. Jeevan Kumar, G. Ranjith Kumar, K. Chandra Babu Naidu, J. Supercond. Nov. Magn. 31 (2018) 1971.

[2] M.H. Phan, S.C. Yu, J. Magn. Magn. Mater. 308 (2007) 325.

[3] V.K. Pecharsky, K.A. Gschneidner Jr., Phys. Rev. Lett. 78 (1997) 4494.

[4] V.K. Pecharsky Jr., K.A. Gschneidner, J. Magn. Magn. Mater. 167 (1997) L179.

[5] H. Wada, Y. Tanabe, Appl. Phys. Lett. 79 (2001) 3302.

[6] F.X. Hu, B.G. Shen, J.R. Sun, Z.H. Cheng, G.H. Rao, X.X. Zhang, Appl. Phys. Lett. 78 (2001) 3675 .

[7] F.X. Hu, B.G. Shen, J.R. Sun, Appl. Phys. Lett. 76 (2000) 3460.

[8] S.O. Manjunatha, A. Rao, V.P.S. Awana, G.S. Okram, J. Magn. Magn. Mater. 394 (2015) 130.

[9] M. Khlifi, M. Bejar, O. EL Sadek, E. Dhahri, M.A. Ahmed, E.H. Hlil, J. Alloys Compd. 509 (2011) 7410.

[10] P.T. Phong, S.J. Jang, B.T. Huy, Y.-I. Lee, I.-J. Lee, J. Mater Sci: Mater Electron 24 (2013) 2292.

[11] Y. Fu, Appl. Phys. Lett. 77 (2000) 118.

[12] H.M. Rietveld, J. Appl. Cryst. 2 (1969) 65.

[13] O.Z. Yanchevskii, A.I. Tovstolytkin, O.I. V'yunov, D.A. Durilin, A.G. Belous, Inorganic Materials 40 (2004) 744.

[14] N. Dodiya, D. Varshney, J. Mol. Struct. 1031 (2013) 104.

[15] S. Hcini, S. Zemni, A. Triki, H. Rahmouni, M. Boudard, J. Alloys Compd. 509 (2011) 1394.

[16] S. Hcini, M. Boudard, S. Zemni, Appl. Phys. A 115 (2014) 985.

[17] A. Arrott, Phys. Rev. 108 (1957) 1394.

[18] S.K. Banerjee, Phys. Lett. 12 (1964) 16.

[19] H.E. Stanley, Introduction to Phase Transitions and Critical Phenomena, Oxford University Press, London, 1971.

[20] S. Hcini, S. Zemni, M. Baazaoui, J. Dhahri, H. Vincent, M. Oumezzine, Solid State Sci. 14 (2012) 644.

[21] B. Widom, J. Chem. Phys. 41 (1964) 1633.

[22] M.E. Fisher, S.K. Ma, B.G. Nickel, Phys. Rev. Lett 29 (1972) 917. 
[23] E. Oumezzine, S. Hcini, E.K. Hlil, E. Dhahri, M. Oumezzine, J. Alloys Compd. 615 (2014) 553.

[24] K. Riahi, I. Messaoui, W.C. Koubaa, S. Mercone, B. Leridon, M. Koubaa, A. Cheikhrouhou, J. Alloys Compd. 688 (2016) 1028.

[25] H. Ben Khlifa, R. M'nassri, W.C. Koubaa, E.K. Hlil, A. Cheikhrouhou. Ceram. Int. 43 (2017) 8709.

[26] I. Walha, M. Smari, T. Mnasri, E. Dhahri. J. Magn. Magn. Mater. 454 (2018) 190.

[27] S. Hcini, M. Boudard, S. Zemni, M. Oumezzine, Ceram. Int. 40 (2014) 16041.

[28] M. Baazaoui, M. Boudard, S. Zemni, Mater. Lett. 65 (2011) 2093.

[29] D.N.H. Nam, N.V. Dai, L.V. Hong, N.X. Phuc, S.C. Yu, M. Tachibana, E. TakayamaMuromachi, J. Appl. Phys. 103 (2008) 043905.

[30] C.P. Reshmi, S.S. Pillai, K.G. Suresh, M.R. Varma, Solid State Sci. 19 (2013) 130.

[31] Y. Sun, W. Tong, Y.H. Zhang, J. Magn. Magn. Mater. 232 (2001) 205.

[32] H. Oesterreicher, F.T. Parker, J. Appl. Phys. 55 (1984) 4334.

[33] V. Franco, J. S. Blazquez, A. Conde, Appl. Phys. Lett, 89 (2006) 222512.

[34] F. Saadaoui, R. M’nassri, A. Mleiki, M. Koubaa, N. Chniba Boudjada, A. Cheikhrouhou, J. Mater. Sci.: Mater. Electron. 28 (2017) 15500.

[35] R. Thaljaoui, W. Boujelben, M. Pekala, K. Pekala, W.C. Koubaa, A. Cheikhrouhou, J. Mater. Sci. 48 (2013) 3894.

[36] A. Selmi, M. Khelifi, H. Rahmouni, R. M'nassri, K. Khirouni, N.C. Boudjada, A. Cheikhrouhou, J. Mater. Sci. 28 (2017) 1901.

[37] J.Y. Law, R.V. Ramanujan, V. Franco, J. Alloys Compd. 508 (2010) 14.

[38] V. Franco, A. Conde, Int. J. Refrig. 33 (2010) 465. 


\section{Table legends}

Table 1: Rietveld refinement of the structural parameters for $\mathrm{La} 0 .{ }_{6} \mathrm{Ca} 0.2 \mathrm{Na}_{0 .} \mathrm{MnO}_{3}$ perovskite. The numbers in parentheses are estimated standard deviations to the last significant digit.

\begin{tabular}{|c|c|c|c|c|}
\hline \multicolumn{4}{|l|}{ Sample } & $\mathrm{La}_{0.6} \mathrm{Ca}_{0.2} \mathrm{Na}_{0.2} \mathrm{MnO}_{3}$ \\
\hline \multicolumn{4}{|l|}{ Space group } & $R \overline{3} c$ \\
\hline \multirow{3}{*}{$\begin{array}{l}\text { Cell } \\
\text { parameters }\end{array}$} & \multicolumn{3}{|l|}{$a(\AA)$} & $5.4859(1)$ \\
\hline & \multicolumn{3}{|l|}{$c(\AA)$} & $13.3963(2)$ \\
\hline & \multicolumn{3}{|l|}{$V\left(\AA^{3}\right)$} & $349.15(1)$ \\
\hline \multirow[t]{12}{*}{ Atoms } & \multirow[t]{4}{*}{$\mathrm{La} / \mathrm{Ca} / \mathrm{Na}$} & Wyckoff Positions & & $6 a$ \\
\hline & & Site Symmetry & & 32 \\
\hline & & Atomic Positions & $(x, y, z)$ & $(0,0,1 / 4)$ \\
\hline & & Isotropic Debye-Waller factor & $B_{\text {iso }}\left(\AA^{2}\right)$ & $0.81(1)$ \\
\hline & \multirow[t]{4}{*}{$M n$} & Wyckoff Positions & & $6 \mathrm{~b}$ \\
\hline & & Site Symmetry & & -3 \\
\hline & & Atomic Positions & $(x, y, z)$ & $(0,0,0)$ \\
\hline & & Isotropic Debye-Waller factor & $B_{\text {iso }}\left(\AA^{2}\right)$ & $0.58(1)$ \\
\hline & \multirow[t]{4}{*}{$O$} & Wyckoff Positions & & $18 \mathrm{e}$ \\
\hline & & Site Symmetry & & 2 \\
\hline & & Atomic Positions & $(x, y, z)$ & $(0.5447(2), 0,1 / 4)$ \\
\hline & & Isotropic Debye-Waller factor & $B_{\text {iso }}\left(\AA^{2}\right)$ & $1.56(1)$ \\
\hline \multirow{3}{*}{$\begin{array}{l}\text { Structural } \\
\text { parameters }\end{array}$} & & Bond length & $d_{M n-O}(\AA)$ & $1.953(2)$ \\
\hline & & Bond angle & $\theta_{M n-O-M n}\left(^{\circ}\right)$ & $165.48(9)$ \\
\hline & & Average crystallites size & $D(n m)$ & 48 \\
\hline \multirow{4}{*}{$\begin{array}{l}\text { Agreement } \\
\text { factors }\end{array}$} & \multicolumn{2}{|c|}{ Profile factor } & $R_{p}(\%)$ & 5.91 \\
\hline & \multicolumn{2}{|c|}{ Weighted profile factor } & $R_{w p}(\%)$ & 8.48 \\
\hline & \multicolumn{2}{|c|}{ Structure factor } & $R_{F}(\%)$ & 3.52 \\
\hline & \multicolumn{2}{|c|}{ Goodness offit } & $\chi^{2}(\%)$ & 3.44 \\
\hline
\end{tabular}


Table 2: Comparison of the critical exponents values of $\mathrm{La}_{0.6} \mathrm{Ca}_{0.2} \mathrm{Na}_{0.2} \mathrm{MnO}_{3}$ perovskite (present work) with those of the theoretical models.

\begin{tabular}{|c|c|c|c|c|c|c|}
\hline Material & Technique & $T_{C}(K)$ & $\boldsymbol{\beta}$ & $\gamma$ & $\delta$ & Ref. \\
\hline Mean-field model & & & 0.5 & 1.0 & 3.0 & [20] \\
\hline 3D- Heisenberg model & & & $0.365 \pm 0.003$ & $1.336 \pm 0.004$ & $4.80 \pm 0.04$ & [20] \\
\hline 3D- Ising Model & & & $0.325 \pm 0.002$ & $1.24 \pm 0.002$ & $4.82 \pm 0.02$ & [20] \\
\hline Tricritical mean-field model & & & 0.25 & 1.0 & 5.0 & [20] \\
\hline \multirow{5}{*}{$\mathrm{La}_{0.6} \mathrm{Ca}_{0.2} \mathrm{Na}_{0.2} \mathrm{MnO}_{3}$} & Modified & $274.69 \pm 0.74$ & $0.481 \pm 0.009$ & - & - & \multirow[t]{2}{*}{ Present work } \\
\hline & $\begin{array}{l}\text { Arrott } \\
\text { plots }\end{array}$ & $274.19 \pm 0.56$ & - & $1.012 \pm 0.012$ & - & \\
\hline & Kouvel- & $274.87 \pm 0.14$ & $0.492 \pm 0.004$ & - & - & \multirow[t]{2}{*}{ Present work } \\
\hline & $\begin{array}{l}\text { Fisher } \\
\text { method }\end{array}$ & $274.63 \pm 0.19$ & - & $1.022 \pm 0.001$ & - & \\
\hline & $\begin{array}{l}\text { Critical } \\
\text { isotherm }\end{array}$ & - & - & - & $3.030 \pm 0.014$ & Present work \\
\hline
\end{tabular}


Table 3: Magnetocaloric parameters at $\mu_{0} H=5 \mathrm{~T}$ for $\mathrm{La}_{0.6} \mathrm{Ca}_{0.2} \mathrm{Na}_{0.2} \mathrm{MnO}_{3}$ perovskite (present work) compared with those found at the same applied magnetic field for other perovskite systems.

\begin{tabular}{|c|c|c|c|c|c|}
\hline Composition & $T_{C}(K)$ & $\Delta H(T)$ & $\left|\Delta S_{M}^{\max }\right|\left(J \cdot K^{-1} \cdot K^{-1}\right)$ & $R C P\left(J . K^{-1}\right)$ & $\operatorname{Ref}$. \\
\hline $\mathrm{La}_{0.6} \mathrm{Ca}_{0.2} \mathrm{Na}_{0.2} \mathrm{MnO}_{3}$ & 275 & 5 & 3.09 & 214 & Present work \\
\hline $\mathrm{La}_{0.6} \mathrm{Pr}_{0.1} \mathrm{Ba}_{0.3} \mathrm{MnO}_{3}$ & 215 & 5 & 1.97 & 230 & {$[23]$} \\
\hline $\mathrm{La}_{0.6} \mathrm{Pr}_{0.1} \mathrm{Ba}_{0.3} \mathrm{Mn}_{0.9} \mathrm{Ni}_{0.1} \mathrm{O}_{3}$ & 162 & 5 & 1.31 & 123 & {$[23]$} \\
\hline $\mathrm{La}_{0.78} \mathrm{Dy}_{0.02} \mathrm{Ca}_{0.2} \mathrm{MnO}_{3}$ & 312 & 5 & 7.10 & 214.78 & {$[24]$} \\
\hline $\operatorname{Pr}_{0.8} \mathrm{~K}_{0.2} \mathrm{MnO}_{3}$ & 160 & 5 & 7.23 & 274.13 & {$[25]$} \\
\hline $\mathrm{La}_{0.6} \mathrm{Ca}_{0.4} \mathrm{MnO}_{3}$ & 269 & 5 & 6.59 & 221 & {$[26]$} \\
\hline $\mathrm{La}_{0.6} \mathrm{Ca}_{0.3} \mathrm{Ag}_{0.1} \mathrm{MnO}_{3}$ & 267 & 5 & 8.24 & 264 & [26] \\
\hline $\mathrm{Nd}_{0.67} \mathrm{Ba}_{0.33} \mathrm{MnO}_{3}$ & 145 & 5 & 3.91 & 265 & {$[27]$} \\
\hline $\mathrm{Nd}_{0.67} \mathrm{Ba}_{0.33} \mathrm{Mn}_{0.98} \mathrm{Fe}_{0.02} \mathrm{O}_{3}$ & 134 & 5 & 2.97 & 242 & {$[27]$} \\
\hline $\mathrm{La}_{0.67} \mathrm{Ba}_{0.33} \mathrm{Mn}_{0.95} \mathrm{Fe}_{0.05} \mathrm{O}_{3}$ & 271 & 5 & 2.54 & 246 & {$[28]$} \\
\hline $\mathrm{Pr}_{0.67} \mathrm{Ba}_{0.33} \mathrm{Mn}_{0.95} \mathrm{Fe}_{0.05} \mathrm{O}_{3}$ & 128 & 5 & 3.09 & 287 & {$[28]$} \\
\hline $\mathrm{La}_{0.7} \mathrm{Sr}_{0.3} \mathrm{Mn}_{0.95} \mathrm{Al}_{0.05} \mathrm{O}_{3}$ & 332 & 5 & 4.4 & - & [29] \\
\hline $\mathrm{La}_{0.67} \mathrm{Sr}_{0.33} \mathrm{Mn}_{0.95} \mathrm{Ni}_{0.05} \mathrm{O}_{3}$ & - & 5 & 3.2 & - & {$[30]$} \\
\hline $\mathrm{La}_{0.67} \mathrm{Sr}_{0.33} \mathrm{Mn}_{0.9} \mathrm{Ni}_{0.1} \mathrm{O}_{3}$ & 290 & 5 & 3 & 132 & {$[30]$} \\
\hline $\mathrm{La}_{0.67} \mathrm{Sr}_{0.33} \mathrm{Mn}_{0.9} \mathrm{Co}_{0.1} \mathrm{O}_{3}$ & 328 & 5 & 5.00 & 200 & {$[31]$} \\
\hline
\end{tabular}




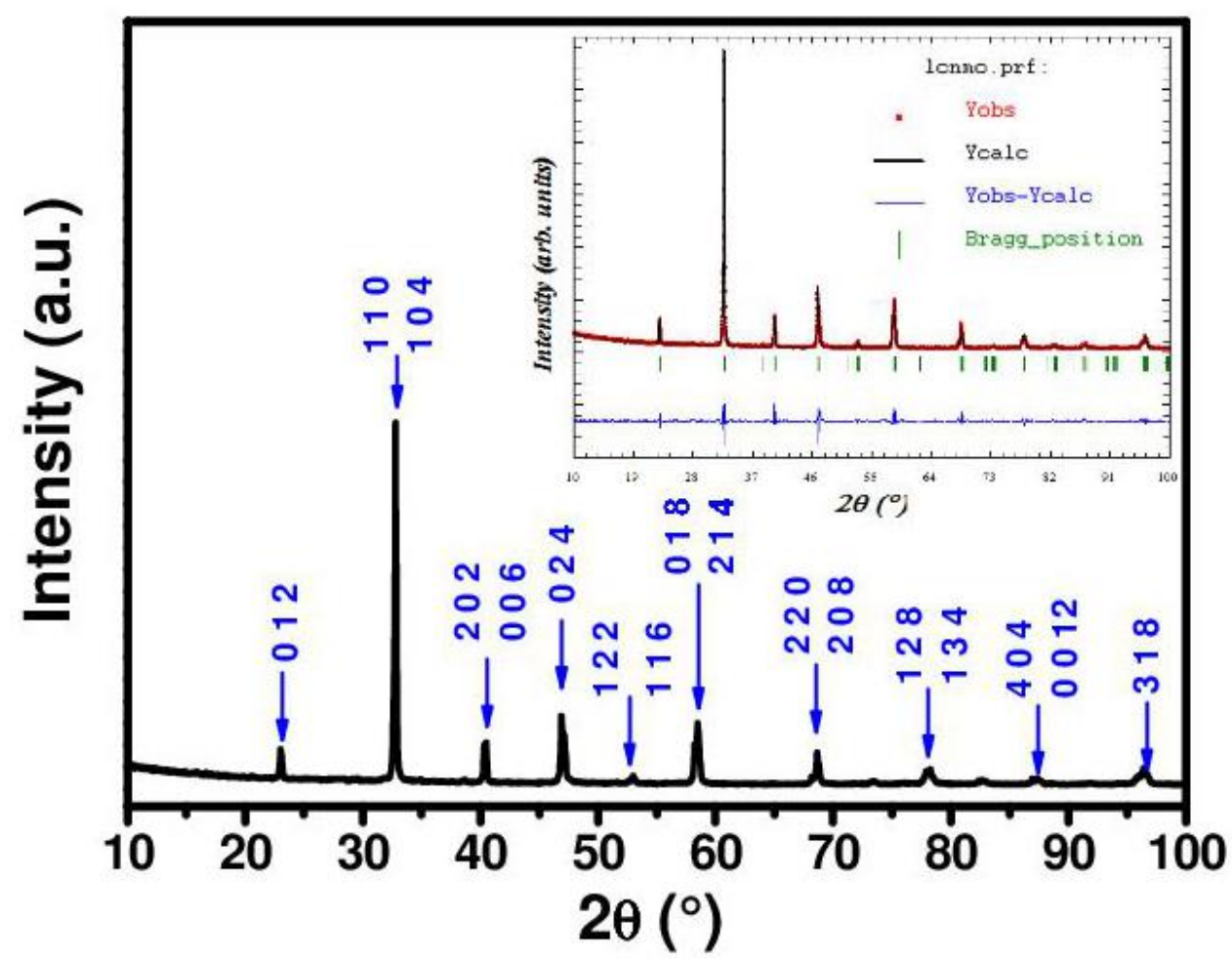

Fig. 1: Main panel: X-ray diffraction pattern for $\mathrm{La}_{0.6} \mathrm{Ca}_{0 .} \mathrm{Na}_{0.2} \mathrm{MnO}_{3}$ perovskite. All peaks of the perovskite phase are indexed in the hexagonal setting of the rhombohedral $R \overline{3} c$ symmetry. The inset shows the Rietveld analysis of XRD pattern. The bottom line (blue) represents the difference between the XRD data (red) and calculated fit (black), and the green lines are Bragg positions. 

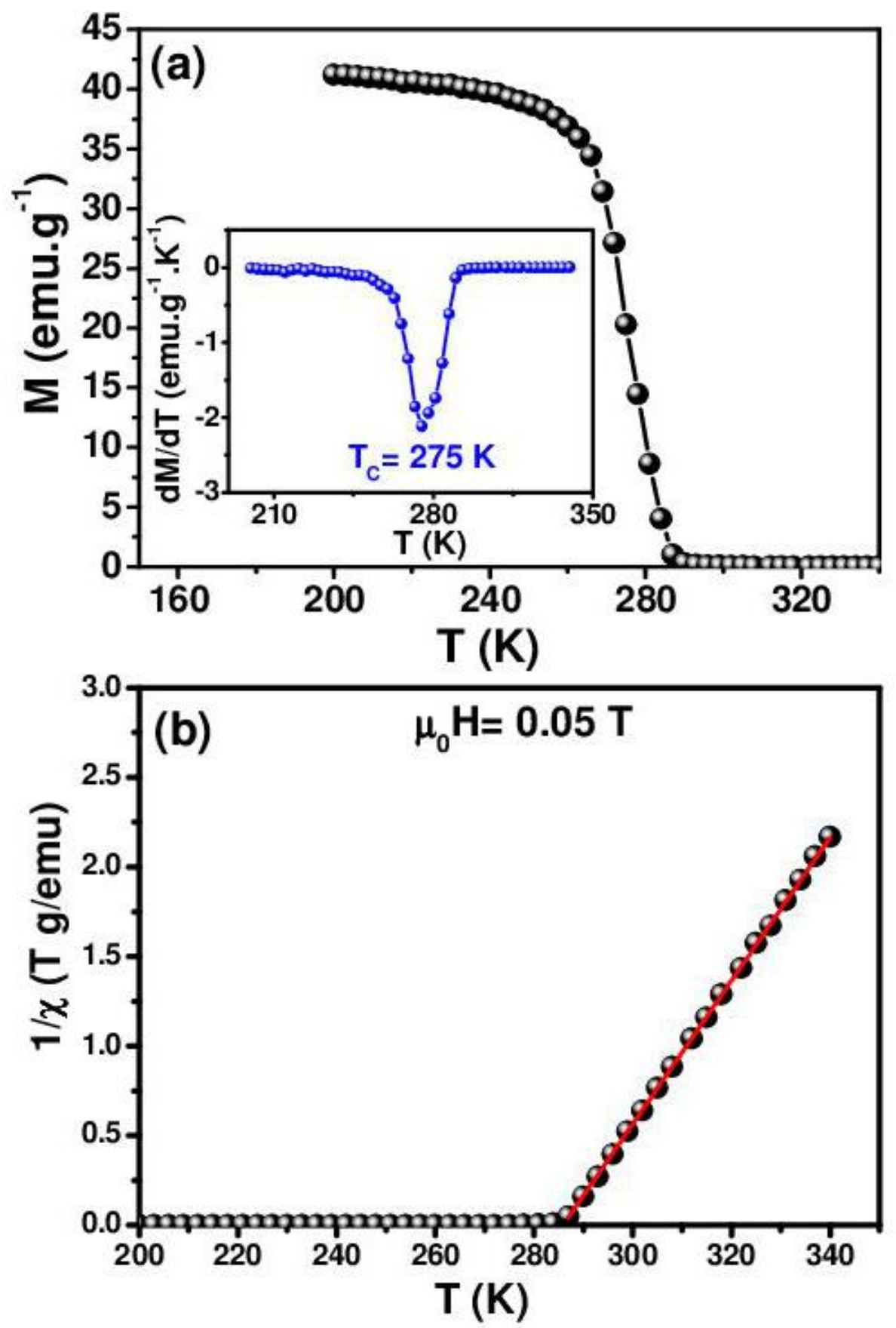

Fig. 2: (a) Temperature dependence of magnetization and graph of $d M / d T v s$. $T$ under magnetic field of $\mu_{0} H=0.05 \mathrm{~T}$ for $\mathrm{La}_{0.6} \mathrm{Ca}_{0.2} \mathrm{Na}_{0.2} \mathrm{MnO}_{3}$ perovskite. (b) Temperature dependence of the inverse of magnetic susceptibility fitted using the Curie Weiss law. 

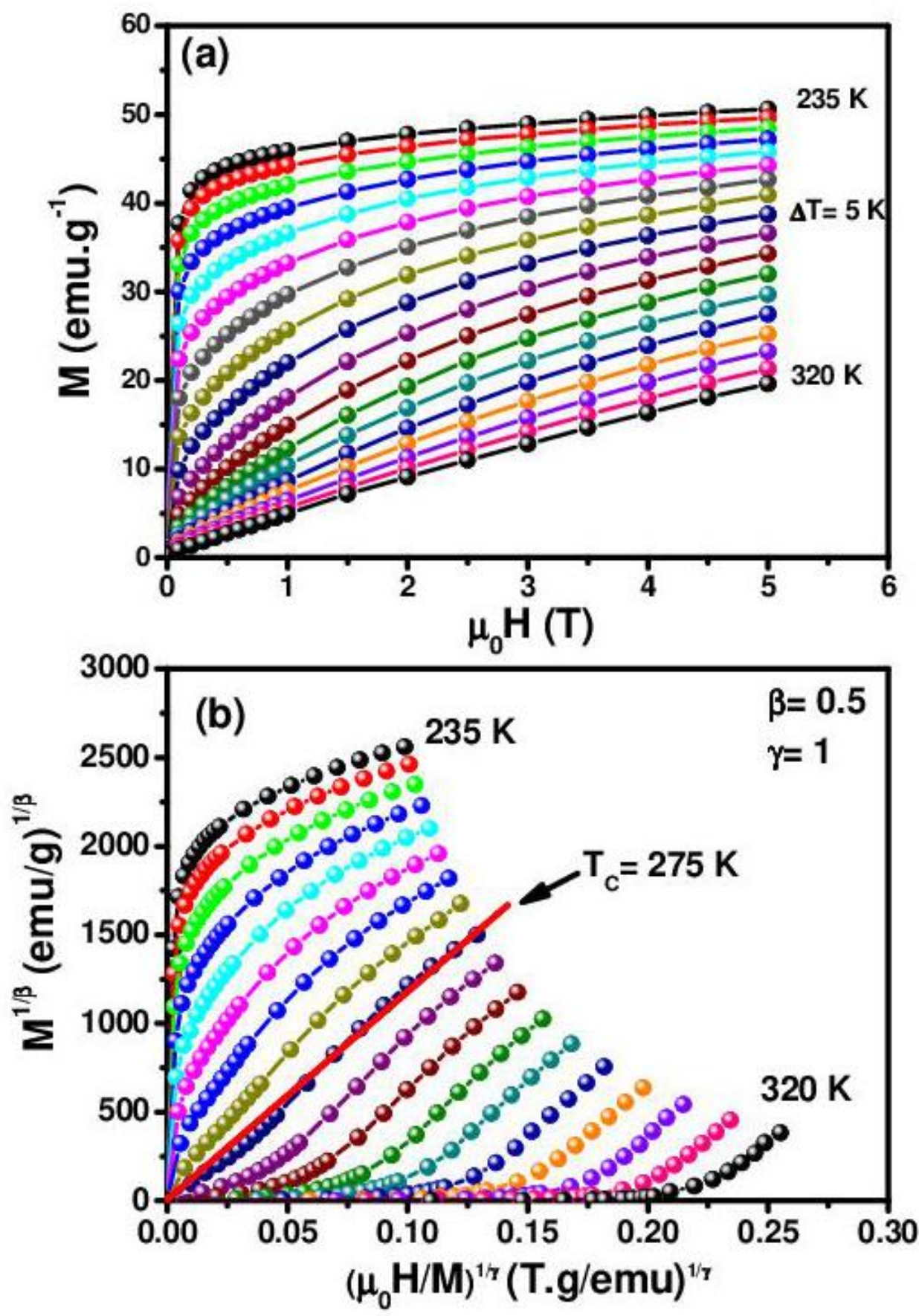

Fig. 3: (a) $M\left(\mu_{0} H, T\right)$ curves and (b) Arrott plots around $T_{C}$ for $\mathrm{La}_{0.6} \mathrm{Ca}_{0.2} \mathrm{Na}_{0.2} \mathrm{MnO}_{3}$ perovskite. 

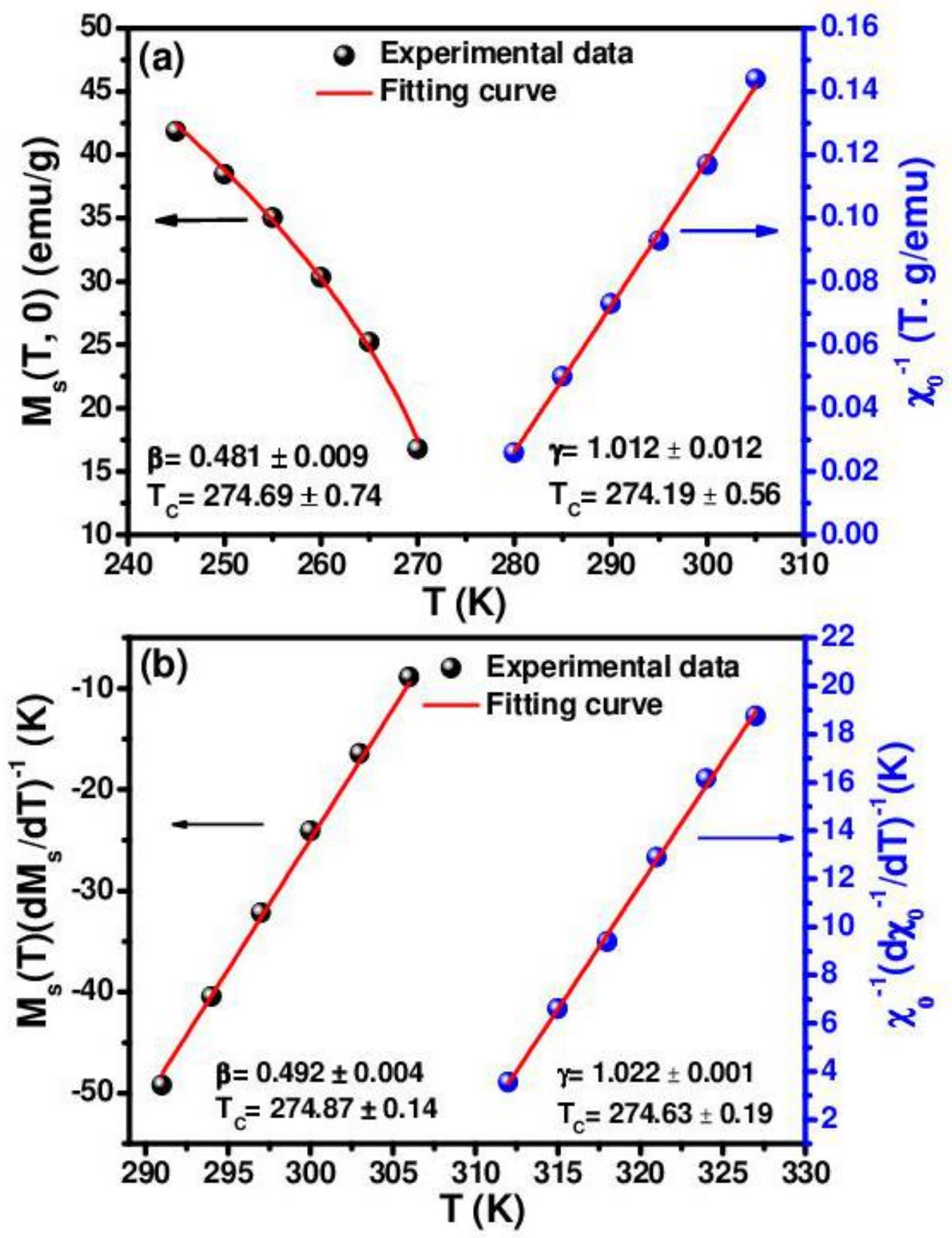

Fig. 4: (a) Spontaneous magnetization $M_{s}(T)$ (left-axis) and inverse initial susceptibility $\chi 0^{-}$ ${ }^{I}(T)$ (right-axis) as a function of temperature fitted according to Eqs. (5) and (6), respectively for $\mathrm{La}_{0.6} \mathrm{Ca}_{0.2} \mathrm{Na}_{0.2} \mathrm{MnO}_{3}$ perovskite. (b) Kouvel-Fisher plots for the spontaneous magnetization $M_{s}(T)$ (left-axis) and the inverse initial susceptibility $\chi 0^{-1}(T)$ (right-axis) fitted according to Eqs. (7) and (8), respectively. 


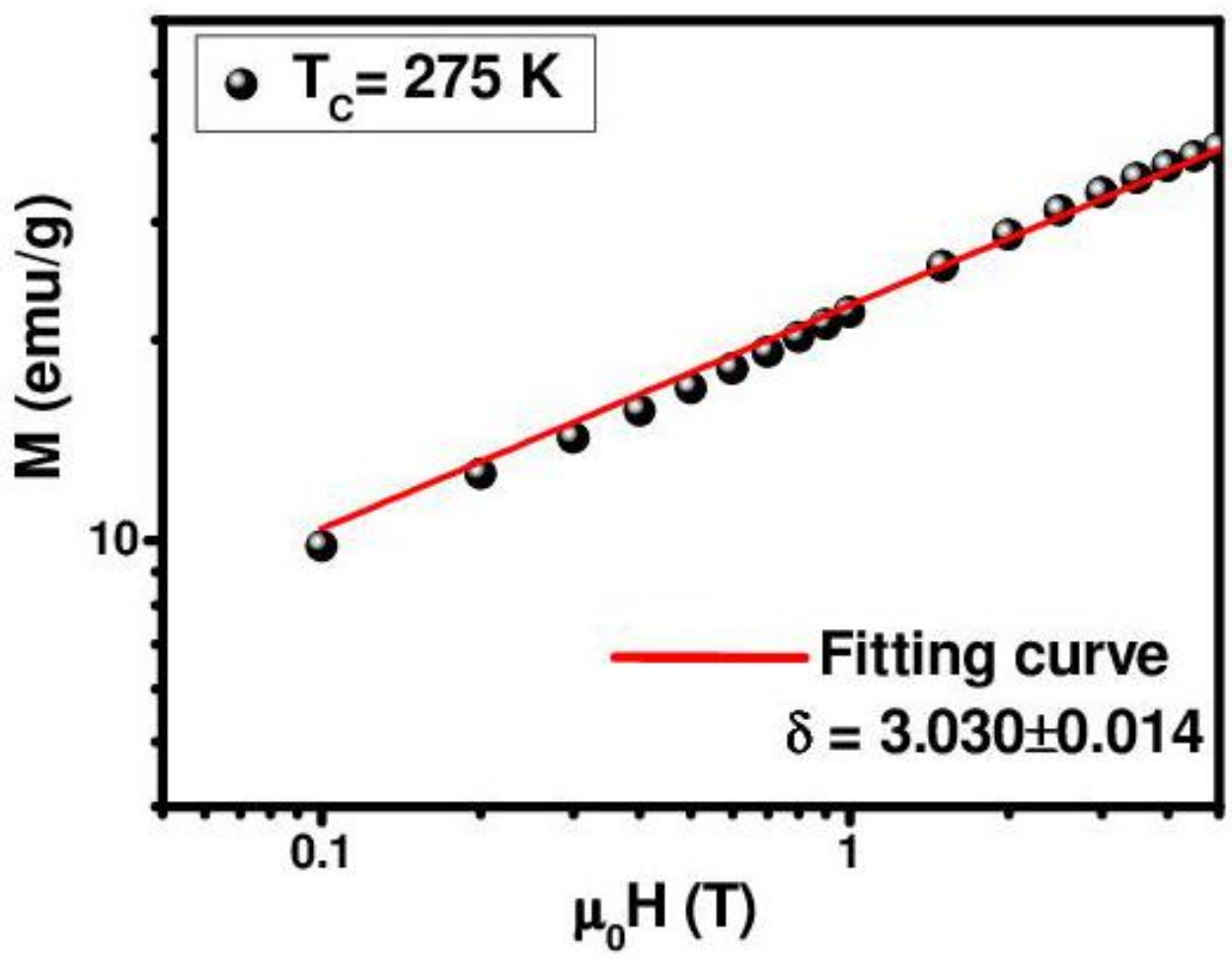

Figs. 5: Isothermal $M\left(T_{C}, \mu_{0} H\right)$ plot at $\log -\log$ scale for $\mathrm{La}_{0 .} \mathrm{Ca}_{0.2} \mathrm{Na}_{0 .} \mathrm{MnO}_{3}$ perovskite adjusted following Eq. (9). 


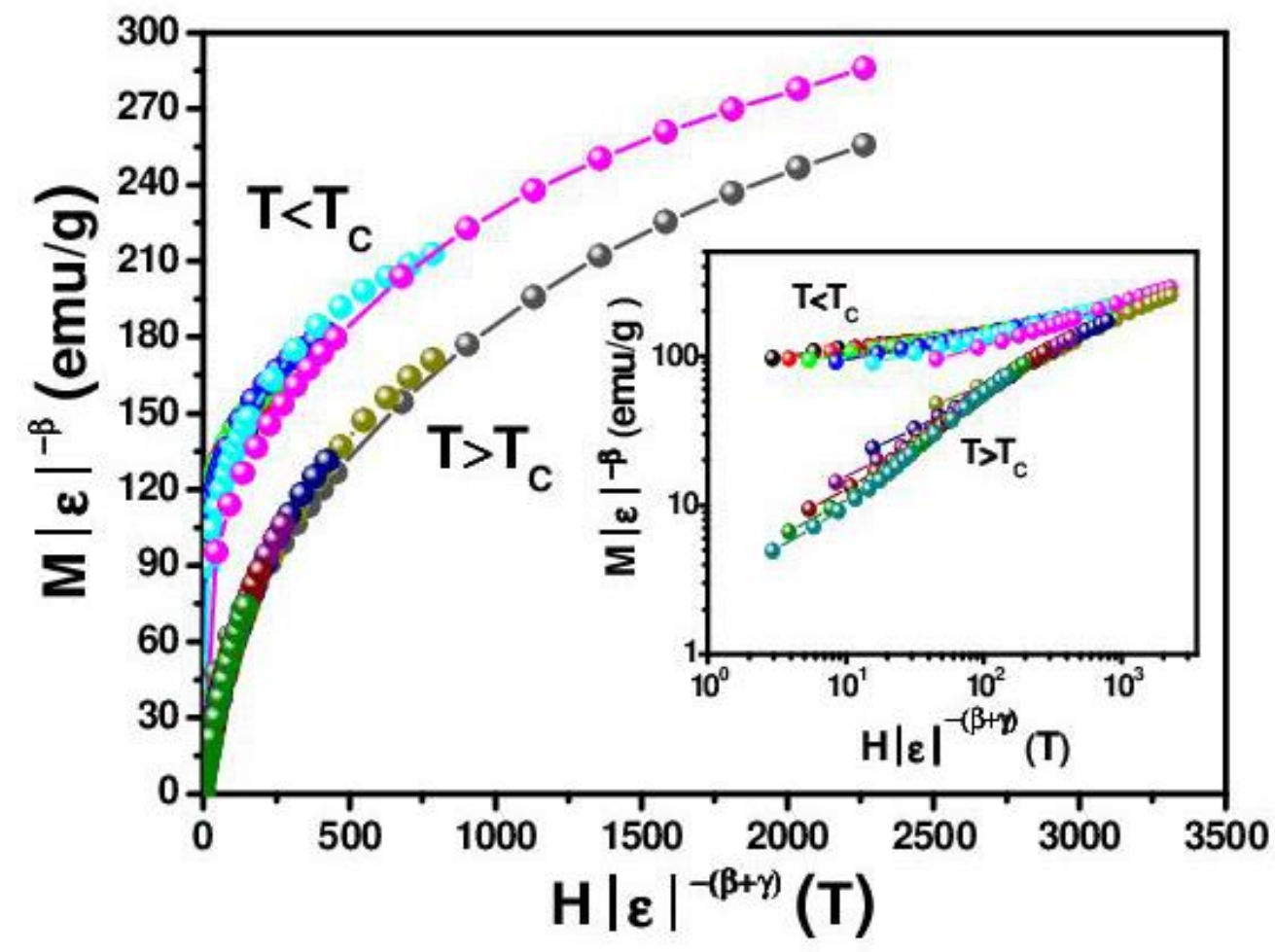

Figs. 6: Scaling plots for $\mathrm{La}_{0.6} \mathrm{Ca}_{0}{ }_{2} \mathrm{Na}_{0 .} \mathrm{MnO}_{3}$ perovskite below and above $T_{\mathrm{C}}$ using $\beta$ and $\gamma$ determined by the Kouvel-Fisher method. The inset represents the same plot in log-log scale. 

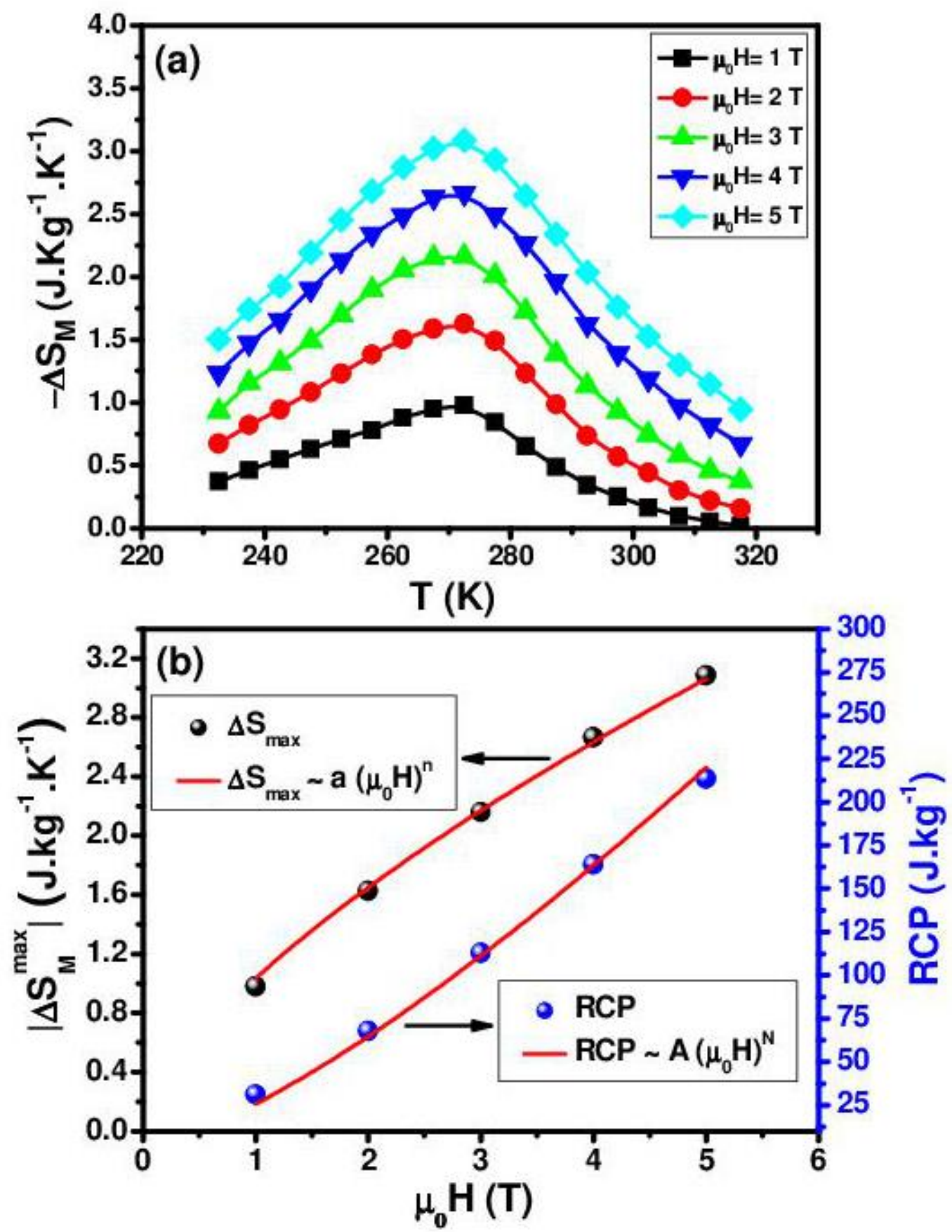

Fig. 7: (a) Temperature dependence of the magnetic entropy change at various applied magnetic fields for $\mathrm{La}_{0.6} \mathrm{Ca} 0.2 \mathrm{Na}_{0.2} \mathrm{MnO}_{3}$ perovskite. (b) $\left|\Delta S_{M}^{\max }\right|$ vs. $\mu_{0} H$ curve fitted using $\Delta S_{m}=a\left(\mu_{0} H\right)^{n}$ power low, and $R C P$ vs. $\mu_{0} H$ curve fitted using $R C P=A\left(\mu_{0} H\right)^{N}$ power low. 